\title{
Plataforma logística: análise estratégica dos benefícios no setor conserveiro gaúcho
}

\author{
Patricia Costa Duarte, Dr. (PPGEP/UFRGS) \\ Professora Sociedade Educacional de Santa Catarina, Instituto Superior de Tecnologia \\ pcduarte_rs@yahoo.com.br
}

Francisco José Kliemann Neto, Dr.

Programa de Pós-graduação em Engenharia de Produção - UFRGS

kliemann@producao.ufrgs.br

\begin{abstract}
Esse artigo apresenta o mapa estratégico para apoiar a implantação de uma Plataforma Logística, fazendo uma relação entre estratégias pretendidas e custos logísticos inseridos nos processos de movimentação de mercadorias no mercado interno, exportação e importação. Para isso, descreve os processos atuais na movimentação de mercadorias, fazendo um levantamento dos custos logísticos inseridos em cada atividade logística, apontando os elementos mais importantes e que absorvem a maioria destes custos. Com a observação dos processos atuais foi possível estruturar de forma genérica o mapa estratégico, posteriormente aplicado no setor conserveiro, localizado no sul do Estado, visando apontar onde e em quais situações é interessante para as indústrias de conservas utilizarem os serviços propostos por uma Plataforma Logística.
\end{abstract}

Palavras-chave: plataforma logística; estratégia; custos logísticos

The objective of this paper is to develop a strategic map to support the implantation of a Logistic Platform. It was created a relationship between projected strategies and logistic cost included in the delivery processes of the domestic market of exportation and importation. Based on this, the current processes for goods delivery were described, developing an analysis of the logistic cost inserted in each logistic activity, pointing the most important elements that absorb most of the logistic cost. In a generic way, observing the current processes, it was possible to structure a strategic map. Later, the map was applied in the Conserve Production sector, located in the south of the state. The application of the map addressed where and in which situations is interesting for the conserve industries to use the services proposed by the Logistic Platform.

Key-words: logistic platform; strategies; logistic cost

\section{Introdução}

Com a extensão geográfica que as empresas atingiram através da competição global dos mercados e a constante busca por soluções para manter vantagens competitivas diante desta expansão global, destacam-se como soluções a formação de agrupamentos logísticos, como forma de cooperar e estimular a competitividade entre os parceiros/rivais da cadeia logística. A formação de agrupamentos entre os membros da cadeia logística é uma prática inovadora. Existem alguns estudos a respeito da viabilidade e da localização de organizações logísticas, no sentido de sobreviver ao mercado global, bem como atingir e manter uma vantagem estratégica competitiva (DUARTE, 2003).

Segundo Dornier et al. (2000), "a globalização forçou rápidas mudanças em companhias historicamente imunes à competição estrangeira", estimulando a organização do território nacional e definindo o que é mais importante na determinação da capacidade competitiva global, sabendo o que isso significa em termos de custos, demanda, treinamento de trabalhadores e desenvolvimento regional. 
Diante da competição, as empresas necessitam definir suas políticas internas, redefinindo as arquiteturas organizacionais e organizando as estratégias para competir e sobreviver no ambiente global, aliando qualidade e flexibilidade aos custos competitivos. Com a extensão geográfica dos elementos da cadeia logística (fornecedores, produção e distribuição até o cliente final), há uma crescente necessidade de se organizarem as instalações para atender os usuários clientes, melhorando a competitividade das empresas e viabilizando as atividades logísticas.

Para Lacerda (2000), "a definição da localização de instalações em uma cadeia logística, é um problema comum e dos mais importantes, pois decorre de altos investimentos envolvidos e profundos impactos sobre os custos logísticos". Os efeitos da localização de instalações podem até mesmo envolver questões culturais, políticas de governo e de custos.

Avaliando os efeitos da localização dentro da cadeia logística, autores tratam do agrupamento de empresas como uma maneira de maximizar a relação entre empresas, e entre empresas e clientes para desta forma, obter vantagens competitivas com a redução dos custos logísticos. Dentre as várias definições de agrupamentos que visam à redução dos custos e o aumento da vantagem competitiva, criando ambientes propícios à oferta de serviços logísticos, destacam-se a criação de Plataformas Logísticas.

As Plataformas Logísticas surgiram na França na década de 60 como conseqüência do avanço dos estudos em gerenciamento de operações, tendo como objetivo inicial reduzir o fluxo de materiais distribuídos de forma desordenada pelos terminais de cargas da periferia das grandes cidades (BACOVIS, 2007).

Uma Plataforma Logística tem a finalidade de aumentar a eficiência da organização; seja esta um conjunto de empresas em uma região ou até mesmo estado ou país, criando empregos, melhorando o valor e o tempo de serviços e, desta forma, aumentando a competitividade. Segundo Boudouin (1996), os investimentos se dividem entre o "público: 'urbanização dos terrenos', implantação de infraestruturas de transportes e, eventualmente de construções alugadas a empresas de serviços e operadoras e, o privado: construção dos locais no interior dos quais são tratadas as mercadorias e ofertados os serviços".

Deve-se, enfim, considerar o contexto estratégico onde a Plataforma Logística estará inserida, tais como o fluxo e a diversidade de produtos que circulem pela região, bem como os vários clientes que se beneficiem com a movimentação, armazenagem e transporte através deste sistema logístico e conseqüentemente, justifiquem seus investimentos e infra-estrutura. Para isso, foi desenvolvido um mapa estratégico para apoiar a implantação de uma Plataforma Logística, no qual o objetivo maior é medir as vantagens ou não para qualquer cliente/usuário.

O desenvolvimento deste mapa estratégico iniciou com a observação e detalhamento dos processos de transporte, movimentação, armazenagem e distribuição de produtos no mercado interno, exportação e importação. Este processo de desenvolvimento pode ser visualizado no item 4 deste artigo. Estes processos logísticos apontaram as atividades logísticas e seus respectivos custos para cada mercado de atuação, nas hipóteses: com e sem a utilização de Terminais Alfandegados de uso público; para os procedimentos aduaneiros nos processos de exportação e importação de produtos, sendo possível generalizar os processos para cada mercado de atuação, apontando aspectos a serem melhor analisados e diagnosticados em uma situação real com a utilização dos serviços propostos por uma Plataforma Logística.

Tal mapa estratégico baseou-se na importância de haver um instrumento de avaliação que permitisse a aplicação aos diversos usuários/clientes interessados em buscar uma vantagem competitiva diante do cenário logístico atual, apontando estratégias a serem repensadas e, conseqüentemente minimizando custos logísticos inseridos nos processos de circulação de produtos.

O assunto Plataforma Logística desperta há alguns anos, o interesse dos governos na Europa. No Brasil, este assunto ainda é pouco divulgado, discute-se a criação de Plataformas no Rio Grande do Sul, Bahia e Goiás. Como o tema tem despertado interesse, este artigo tem como objetivo apresentar o mapa estratégico desenvolvido para apoiar a implantação de uma Plataforma Logística em um possível usuário/cliente no Rio Grande do Sul (indústrias do setor de produção conserveiro), apontando as necessidades com relação às atividades logísticas desempenhadas na atual situação de transporte, movimentação e armazenagem de produtos além de, diagnosticar de que maneira uma Plataforma Logística beneficiaria este usuário do sistema logístico.

\section{Definição de uma Plataforma Logística}

Segundo Duarte e Rodrigues (1998), com as exigências em relação à produtividade e a qualidade do serviço oferecido aos clientes, a diversidade da produção, as grandes distâncias, a pressão para reduzir os custos e a competição entre as empresas, a Europa se tornou um local onde estes temas fazem parte de políticas nacionais e regionais. A vontade de agir sobre a organização e a circulação de mercadorias fez com que os europeus criassem localizações logísticas, para melhorar o nível de serviço e dinamizar os custos. Estas localizações logísticas são ana- 
lisadas em três tipos:

... O sítio logístico que corresponde a um lugar fisicamente bem delimitado, sobre o qual intervenha um único operador;

... A zona logística que corresponde a um espaço bem delimitado, com diversos operadores e com facilidades de ramificações multimodais, além de agrupar vários sítios logísticos;

... O pólo logístico que está num espaço levemente delimitado, geralmente muito amplo, que exibe uma concentração de atividades logísticas e que agrupa vários sítios e zonas logísticas (COLIN, 1996).

Com todas essas preocupações surgem as Plataformas Logísticas como uma alternativa para a organização dos espaços e circulação de bens e serviços. Segundo Duarte (1999b), a Plataforma Logística é composta de três subzonas com funções especiais:

... Subzona de serviços gerais destinada: ao homem com áreas de recepção, informação, acomodação e alimentação, bancos, agência de viagens; à máquina, com áreas de estacionamento, abastecimento e reparos e; à empresa, com áreas de serviços de alfândega, administração e comunicação.

... Subzona de transportes: agrupa infra-estruturas de grandes eixos de transportes. É muito importante que a plataforma seja multimodal e possua terminais multimodais.

... Subzona destinada aos operadores logísticos: dando condições de prestar serviços de fretamento, corretagem, assessoria comercial e aduaneira, aluguel de equipamentos, armazenagem, transporte e distribuição.

As Plataformas Logísticas têm despertado interesse seja a nível público ou privado e seu desenvolvimento seja em âmbito local, regional ou nacional. Mas o que vem a ser uma Plataforma e suas reais vantagens, nem sempre recebem as atenções necessárias.

Uma Plataforma Logística é o local da máxima eficiência logística e da perfeita otimização dos serviços de transporte, armazenagem, distribuição e atividades correlatas, além da desburocratização e agilização das operações aduaneiras. Deve possuir um eficiente sistema de transporte multimodal e uma rede informatizada que conecte os diversos pontos deste macrosistema logístico.

A importância de uma Plataforma Logística está em viabilizar ações que permitam enfrentar e criar alternativas para as organizações que utilizarem seus serviços, face à concorrência de mercado e aos diversos componentes logísticos. As alternativas implementadas dentro do sistema logístico levam ao aumento da competitividade, pois possibilitam, através da integração dos componentes logísticos, o alcance de matéria-prima vinda do fornecedor, passando por mão-de-obra e equipamentos especializados, um extenso sistema de informação e serviços diferenciados e de qualidade.

É muito importante uma análise da situação geográfica da região onde será desenvolvida a Plataforma Logística. Como está inserida nas relações comerciais regionais, nacionais e internacionais a região em questão. É preciso saber se a região oferece um meio social, ambiental e econômico favorável (bancos, sociedades comerciais e de negócios, atrações turísticas e culturais, hotéis, restaurantes, etc.) e também, se apresenta interligações com grandes eixos de transportes necessários à promoção da Plataforma Logística, tais como: ligações terrestres (rodovias e ferrovias), acessos marítimos, fluviais e aéreos (DUARTE, 1999a).

As Plataformas Logísticas são encontradas em vários países europeus e com vários termos equivalentes:

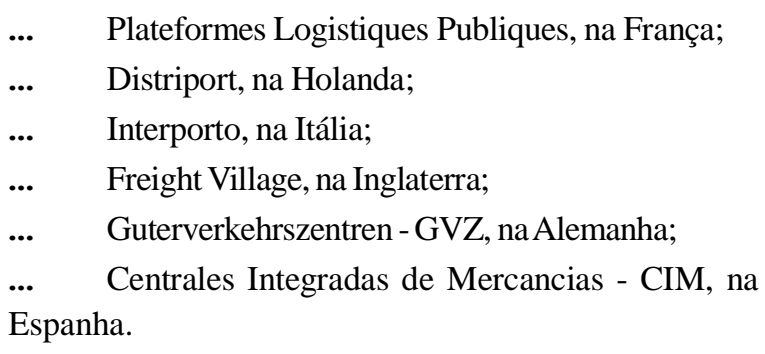

Segundo Duarte (2004), uma Plataforma Logística pode ter sua estrutura desenvolvida em uma área delimitada (Zona Logística), onde intervenham diversos operadores logísticos e agrupem várias atividades logísticas como: armazenagem, transporte, terminais multimodais, distribuição, etc. Esta área mais especificamente pode se tratar de uma empresa ou de um agrupamento das mesmas, uma zona industrial, uma Estação Aduaneira (do Interior ou Fronteira), um porto marítimo ou hidroviário, etc.

Por outro lado, a Plataforma Logística, pode ser vista como uma rede ampla de componentes logísticos. Neste caso, fará parte de um sistema muito amplo que compreende uma área levemente (virtualmente) delimitada que possui uma concentração de diversas atividades logísticas e ainda agrupa muitas zonas logísticas (Pólo Logístico). Tratase aqui, de uma Plataforma Logística que agrupa centros de distribuição, armazéns, estações aduaneiras, terminais retroportuários, portos, ferrovias, terminais rodoviários, conectados a um forte sistema de informação, onde os produtos e serviços circulem rápida e desburocraticamente além das fronteiras da região, Estado ou País, com confiabilidade, segurança e agilidade.

Para simplificar a análise do sistema logístico que engloba a Plataforma Logística, este pode ser dividido em um seg- 
mento de entrada e um segmento de saída. O segmento de entrada da Plataforma Logística envolve o fornecimento de bens e serviços necessários para o início das operações e logística dentro do sistema da plataforma. O segmento de saída engloba bens e serviços que se movem por meio da distribuição física até o cliente final. O sistema logístico completo englobando a Plataforma Logística pode ser observado na Figura 1.

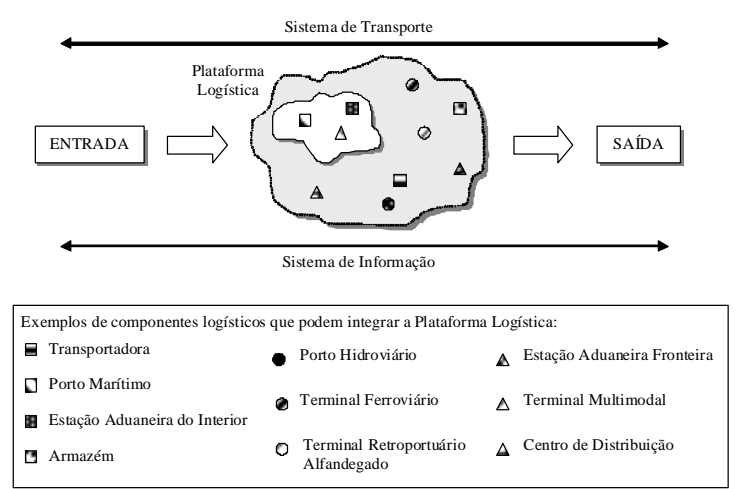

Figura 1 - Sistema logístico que engloba a Plataforma Logística (DUARTE, 2004, p. 82)

Para a manutenção da vantagem competitiva em um sistema logístico disperso geograficamente como, por exemplo, uma Plataforma Logística, o Governo é um importante fator condicionante de subsídios e incentivos fiscais, criando um ambiente propício no qual as empresas possam tornar-se mais competitivas, introduzindo tecnologia e métodos mais sofisticados e penetrando em segmentos mais avançados. A coordenação entre atividades geograficamente dispersa também permite ganhos de escala se as potencialidades de cada componente logístico forem aproveitadas, bem como os custos de cada serviço oferecido pelos diferentes componentes e a flexibilidade para responder às ações dos concorrentes e atender aos clientes de forma diferenciada.

Uma organização do tipo Plataforma Logística pode causar impactos no que diz respeito às oportunidades de desenvolvimentos locais e aproveitamento das potencialidades de cada região. A cultura local é completamente modificada, positiva e/ou negativamente, em função da geração de empregos trazidos com as empresas que decidem se instalar na região, mudando o cenário sócio-econômico com uma avalanche de trabalhadores que se deslocam para estes locais, muitas vezes excluindo a possibilidade de empregos locais, mas também, criando oportunidade de desenvolvimento de cursos técnicos preparatórios de mão-de-obra, criação de universidades, desenvolvimento do potencial turístico e atividades afins como, comércio, restaurantes, hotéis, cinemas, etc.

Uma Plataforma Logística necessita de uma estrutura de informação e transporte, responsável pela conexão de todos os agentes logísticos regionais que compõem este macrosistema, bem como uma modernização tributária de modo que os produtos e serviços circulem sem bi-tributação ou excesso de taxas e impostos cobrados entre origem e destino.

Com modificações como estas apresentadas, a região passa a oferecer vantagens diante de outras regiões e mercados, proporcionando flexibilidade e rapidez na prestação de serviços e conseqüentemente minimização de custos logísticos, valorizando os serviços e os investimentos locais e proporcionado o desenvolvimento de vantagens competitivas, responsáveis pelo desenvolvimento regional, ampliação e divulgação da cultura local e geração de recursos para a região.

\section{Análise econômica do Rio Grande do Sul e estabelecimento de uma infra-estrutura logística}

O Estado do Rio Grande do Sul caracteriza-se por uma área territorial de 282.062km2, proporcional a 3,31\% da área total do País. O Produto Interno Bruto (PIB) no Rio Grande do Sul segundo Schettert (2006), foi de R\$152,7 bilhões em 2005. No mesmo período, o PIB per capita alcançou o valor de R \$14,1 mil.

Segundo Bello e Teruchkin (2006), com relação às exportações do Rio Grande do Sul em 2005, estas somaram US\$ 9,457 bilhões, apresentando um crescimento de apenas 5,0\% em relação aos primeiros 11 meses de 2004. Esse percentual de crescimento foi bem inferior àquele registrado pelo Brasil no mesmo período (23,1\%), denotando uma perda de dinamismo das exportações gaúchas em relação às brasileiras. Em decorrência, a participação do RS no total exportado pelo País, que, em 2004, representou 10,3\%, caiu para $8,8 \%$ em 2005. Mesmo perdendo representatividade, o Estado ainda se manteve como o terceiro maior exportador do Brasil, atrás apenas de São Paulo e de Minas Gerais, os quais responderam por, respectivamente, $32,2 \%$ e $11,4 \%$ das vendas externas brasileiras no período em análise.

Esta queda se deve a um período nada fácil em 2005 para os exportadores gaúchos. A quebra da safra agrícola, em decorrência da forte estiagem que afetou o Estado, pode ser apontada como a principal causa dos fracos resultados das exportações gaúchas. A queda do dólar e a limitação aos créditos de exportação também colaboraram, mas deve-se destacar que a questão cambial, em especial, afeta todo o País e não apenas o RS.

Analisando-se as exportações do Estado por categoria de uso, observa-se que, em 2005, os bens intermediários principal setor nas vendas externas do RS - reduziram sua participação, caindo de 55,1\% sobre o total das exportações gaúchas em 2004 para 48,9\% em 2005, devido à que- 
da de 9,3\% em suas vendas. Essa perda deveu-se ao fraco desempenho de alimentos e bebidas destinados à indústria, que registraram uma queda de $72,6 \%$ em suas exportações, reflexo da estiagem que afetou a safra agrícola ao longo do ano. Porém o item mais importante nos bens intermediários é o dos insumos industriais, os quais, em 2005, representaram 39,7\% das vendas gaúchas ao exterior e cresceram 10,7\% em relação a 2004. A contrapartida da queda na representatividade dos bens intermediários foi o aumento das exportações de bens de capital (23,3\%) e de bens de consumo (14,6\%). Por decorrência, os bens de capital passaram a responder por $15 \%$, e os bens de consumo, por 33,7\% do total exportado pelo RS. Já as exportações de combustíveis e lubrificantes tiveram um aumento de $317,5 \%$, elevando sua participação na pauta exportadora do Estado de 0,3\% em 2004 para 1,2\% em 2005. Tal taxa deveu-se, em grande parte, à exportação de óleos de petróleo ou de minerais betuminosos, exceto óleos brutos, tendo em vista os acréscimos no volume embarcado (192\%) e no preço do petróleo no mercado internacional. Nessa categoria, destacam-se, pelo valor exportado, o gasóleo (óleo diesel), com crescimento de 1.044\%, e o fuel-oil, ambos adquiridos, sobretudo pelos paísesmembro do Mercosul (BELLO; TERUCHKIN, 2006).

Estes fluxos podem justificar o desenvolvimento de uma Plataforma Logística no Estado, mas também devem ser observados os principais corredores de transportes, pois através de uma rede integrada é possível conectar as diversas organizações. Devem ser feitos um extenso levantamento dos subsistemas rodoviário, hidroviário, ferroviário e aéreo, suas condições de trafegabilidade, infra-estrutura e equipamentos.

Também é necessário fazer um levantamento dos recintos aduaneiros, tanto os interiores quanto os de fronteira, para que os produtos importados ou a serem exportados sofram os processos alfandegários com a maior agilidade possível, evitando a geração de custos extras de armazenagem e outros custos inseridos no processo completo de movimentação de mercadorias.

Segundo Duarte (2005), a Plataforma Logística pode ser entendida em um conceito multidimensional que engloba todas as atividades de operações e logística da cadeia de suprimentos, sendo um conjunto de decisões que procuram atingir e manter a vantagem competitiva. Essas decisões podem ser observadas em duas categorias: como estruturais (que são à base do sistema) e infra-estruturais (que englobam procedimentos, sistemas e alternativas).

Com as análises das potencialidades logísticas, é possível perceber as condições favoráveis para desenvolver uma Plataforma Logística para a movimentação e armazenagem dos produtos regionais e/ou que circulam pela região. Alguns fatores devem ser observados, visto que uma Plataforma opera diversos produtos de diversos cli- entes tais como sazonalidade, tipo de produto (granéis, contêineres, paletes, veículos etc.), tipo de armazenagem (silos, armazéns, pátios, etc.), equipamentos para movimentação, origem/destino dos produtos (importação, exportação, mercado interno, etc.), tempo de armazenagem em recintos aduaneiros, etc.

\subsection{Potenciais clientes/usuários da plataforma logística}

Com as potencialidades logísticas do Estado, é fácil perceber as favoráveis condições do Rio Grande do Sul para desenvolver uma Plataforma Logística Estadual, utilizando os recursos existentes nas várias regiões, as facilidades multimodais e as conexões com outros estados da federação e outros países.

Os potenciais clientes/usuários da Plataforma Logística no estado do Rio Grande do Sul podem ser observados a seguir através de aglomerados de produção, comumente chamados de setores de produção ou setores locais de produção - SLPs. Alguns destes setores de produção definidos no Estado são:

... $\quad$ Setor de Produção de Autopeças: Concentra-se na Serra Gaúcha e produz implementos rodoviários e agrícolas, caminhões e ônibus, peças, autopeças, moldes e matrizes, etc.

... Setor de Produção Conserveiro: Está situado na zona sul do Estado, tratando-se de uma região apropriada à produção de frutas e hortaliças, pelo seu clima temperado.

... Setor de Produção Coureiro-Calçadista: Situado no do Vale dos Sinos, é o maior aglomerado de calçados do mundo abrangendo 26 municípios.

... Setor de Produção de Máquinas e Implementos Agrícolas: Está situado na região noroeste do Estado; "região da produção", seus principais produtos são colheitadeiras, plantadeiras e semeadeiras, silos e armazenagem, tratores, etc.

... $\quad$ Setor de Produção Moveleiro: Está localizado na região nordeste do Estado, dentre seus principais produtos podem-se citar os móveis residenciais, móveis para escritório e móveis institucionais, etc.

O mapa estratégico para apoiar a implantação de uma Plataforma Logística foi preliminarmente aplicado nas indústrias de conservas (frutas e legumes), classificadas como pertencentes ao "setor produtivo conserveiro".

\subsubsection{Setor de produção conserveiro}

Segundo a Associação Gaúcha da Cadeia Agro-industrial de Frutas e Hortaliças (2004), "a indústria da Alimentação é um dos segmentos industriais mais representativos do 
estado do Rio Grande do Sul, o qual é responsável por $6,78 \%$ do PIB estadual e por $20 \%$ do PIB industrial do Rio Grande do Sul".

Neste contexto, os municípios de Arroio do Padre, Arroio Grande, Canguçu, Capão do Leão, Cerrito, Jaguarão, Morro Redondo, Pelotas, Piratini, São Lourenço do Sul e Turuçu do Sul localizados no extremo sul do Estado, são considerados os maiores produtores de "pêssego em calda" do Brasil, responsáveis por $90 \%$ da produção nacional.

Atualmente, o parque industrial é composto por 15 indústrias que absorvem a mão-de-obra direta de aproximadamente 2.000 empregos fixos e 8.000 empregos temporários na safra (outubro - janeiro), além de aproximadamente 12.000 trabalhadores rurais em cerca de 6.000 pequenas e médias propriedades. Segundo o Sindicato das Indústrias de Doces e Conservas de Pelotas - SINDOCOPEL, este cenário durante os anos 70 abrangia aproximadamente 50 indústrias que produziam conservas de pêssego, abacaxi, milho e pepino e, geravam cerca de 25.000 empregos diretos.

O parque industrial hoje produz doces de frutas, conservas, polpas, sucos e frutas congeladas. Na forma de produção do setor conserveiro, 50\% das indústrias que o compõe atuam sazonalmente, produzindo conservas de pêssego, figo e morango, o que representa de 60 a $65 \%$ do volume de produção anual do setor. O restante $50 \%$ das indústrias atuam durante o ano todo, produzindo além das conservas mencionadas anteriormente, produtos com abacaxi, goiaba, abóbora, amora, etc.

Através de um estudo realizado pelo Rio Grande do Sul (2000), as indústrias de conservas mais atuantes e as que conferem maior dinamismo por responderem por mais de $80 \%$ do faturamento deste setor são: Vega, Minuano (Simon's), Olé, Icalda, Oderich e Schramm (única indústria que não participou da amostra). Com base neste estudo, esta foi a amostra adotada para a pesquisa de tese de doutorado, onde através de um questionário dirigido e entrevistas diretas realizadas no mês de maio de 2004, com representantes das indústrias foi possível observar os dados necessários para a aplicação do mapa estratégico.

\section{Considerações iniciais sobre a situação atual na movimentação de mercadorias}

Em uma pesquisa apresentada pelo Coppead/UFRJ, com usuários dos serviços logísticos sobre a "Terceirização Logística no Brasil", os principais resultados levantados foram: redução dos custos (85\%), focar no core-business (76\%), ganhar flexibilidade (68\%) e reduzir ativos (67\%). Entre outros motivos também citados, aparecem aumen- tar níveis de serviço (57\%), aumentar a eficiência operacional (44\%) e gerar novas soluções logísticas (35\%) (MARINO, 2003).

Essas análises reforçam o foco principal do mapa estratégico de uma Plataforma Logística para melhoria dos serviços oferecidos e conseqüentemente, da redução dos custos implícitos no sistema logístico, apresentando uma estratégia logística para que decisões e ponderações com respeito ao critério mais importante em um determinado segmento logístico seja avaliado e seguido para alcançar a vantagem competitiva na cadeia de suprimento completa.

Desta maneira, faz-se necessário uma análise da situação atual, com relação à circulação de mercadorias, seja no âmbito de processos de importação, exportação ou o mercado interno, para que depois possam ser analisadas as vantagens que uma Plataforma Logística poderá oferecer para esses mesmos processos, através dos trade-offs entre custos e objetivos de desempenho. Com o objetivo de subsidiar a elaboração do mapa estratégico, analisaramse os principais mercados potenciais de abrangência de uma Plataforma Logística, elaborando-se um fluxo detalhado das atividades neles desenvolvidas, associandose ainda os custos logísticos a elas associados (DUARTE, 2004).

\subsection{Processo atual para importação de mercadorias}

O processo de movimentação de mercadorias importadas por empresas ou particulares, passa por processos similares, distinguindo-se apenas quando os serviços de despacho aduaneiro são realizados por despachantes ou por operadores logísticos dos TA - Terminais Alfandegados. A seguir podem-se observar estes dois processos, bem como seus custos associados.

\subsubsection{Processo de importação sem plataforma logística e sem TA de uso público}

Este processo tem seu início no momento em que o importador firma contrato com o despachante aduaneiro, que será o responsável pelo recebimento da mercadoria no porto ou aeroporto, bem como as providências para o trânsito interno até que a mercadoria passe pelo despacho aduaneiro na importação, também conhecida como nacionalização da mercadoria.

Este processo de importação pode ser observado detalhadamente na Figura 2, com suas atividades e respectivos custos que só acontecem no processo de importação sem a utilização de um terminal alfandegado. 


\subsubsection{Processo de importação sem plataforma logística e com TAde uso público}

Na Figura 3, pode ser observado o processo completo de importação, que tem seu início a partir do momento em que o cliente firma contrato com o operador logístico do Terminal Alfandegado de uso público. Neste contrato é cadastrado o termo de responsabilidade para ser realiza- do pelo Terminal Alfandegado o trânsito aduaneiro.

\subsection{Processo atual para exportação de mercadorias}

O processo de movimentação de mercadorias exportadas por empresas ou particulares, passa por processos similares entre si e entre o processo de importação.

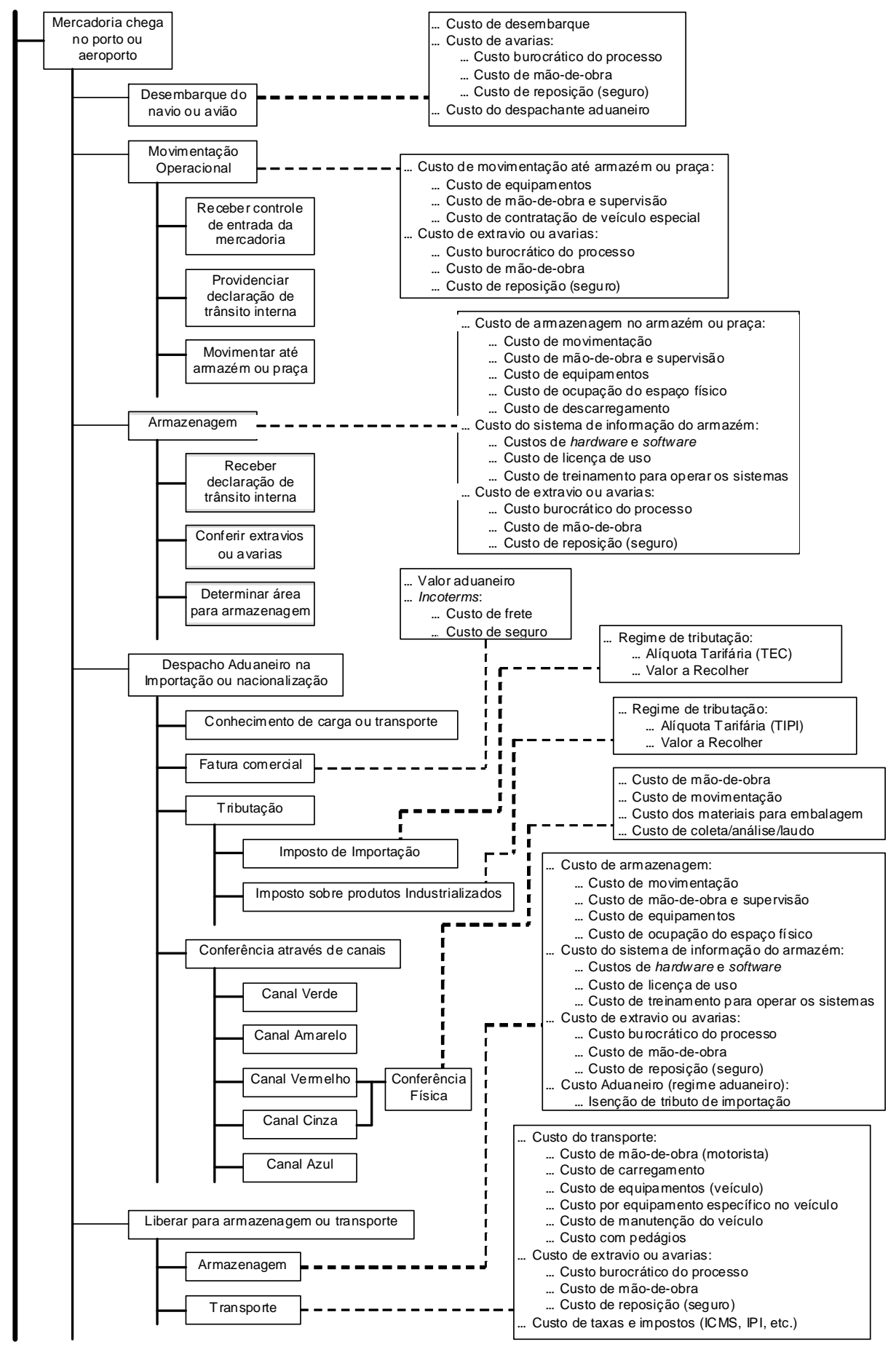

Figura 2 - Processo de importação sem Plataforma Logística e sem TA de uso público (DUARTE, 2004, p.161) 


\subsubsection{Processo de exportação sem plataforma} logística e sem TA de uso público

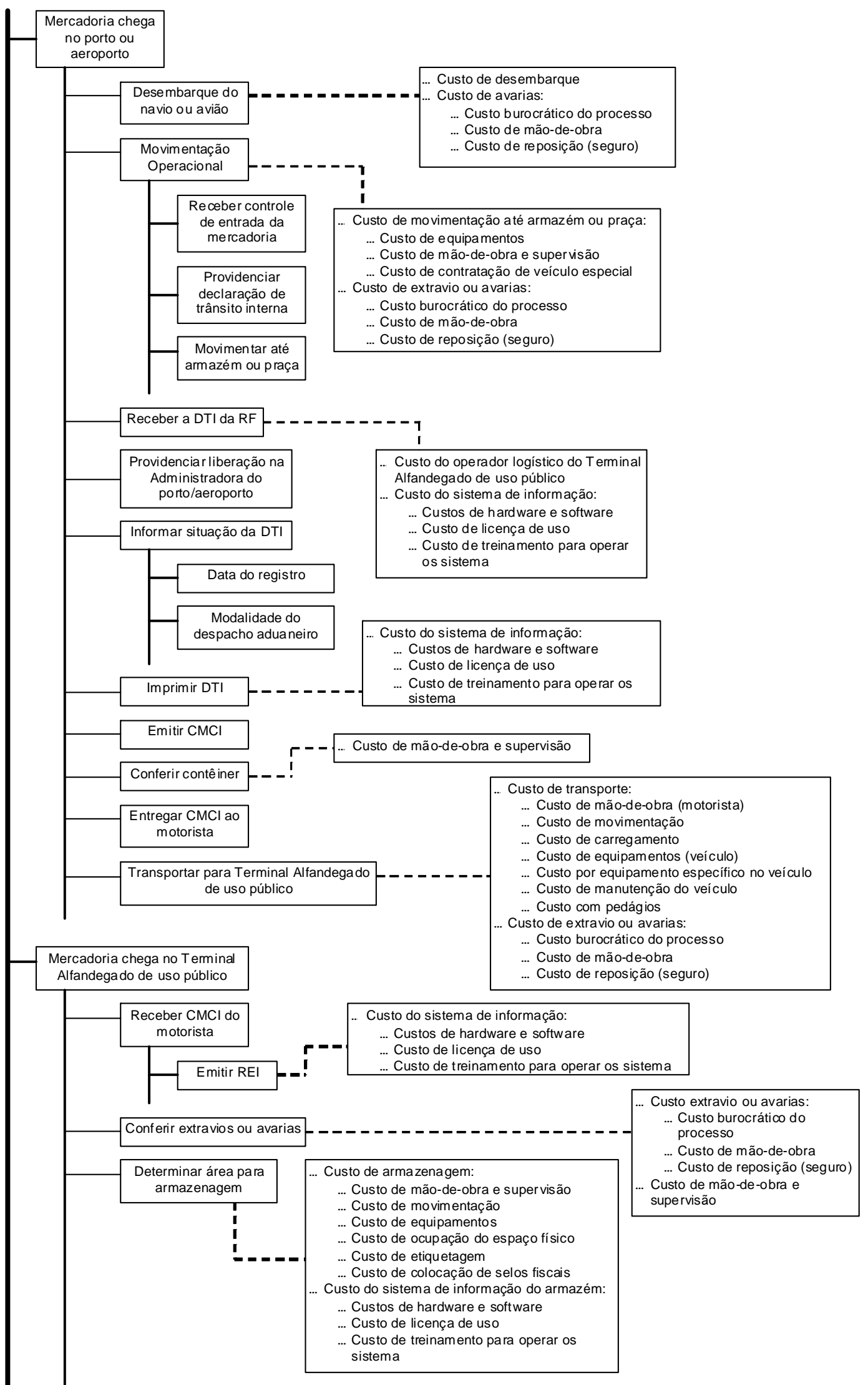




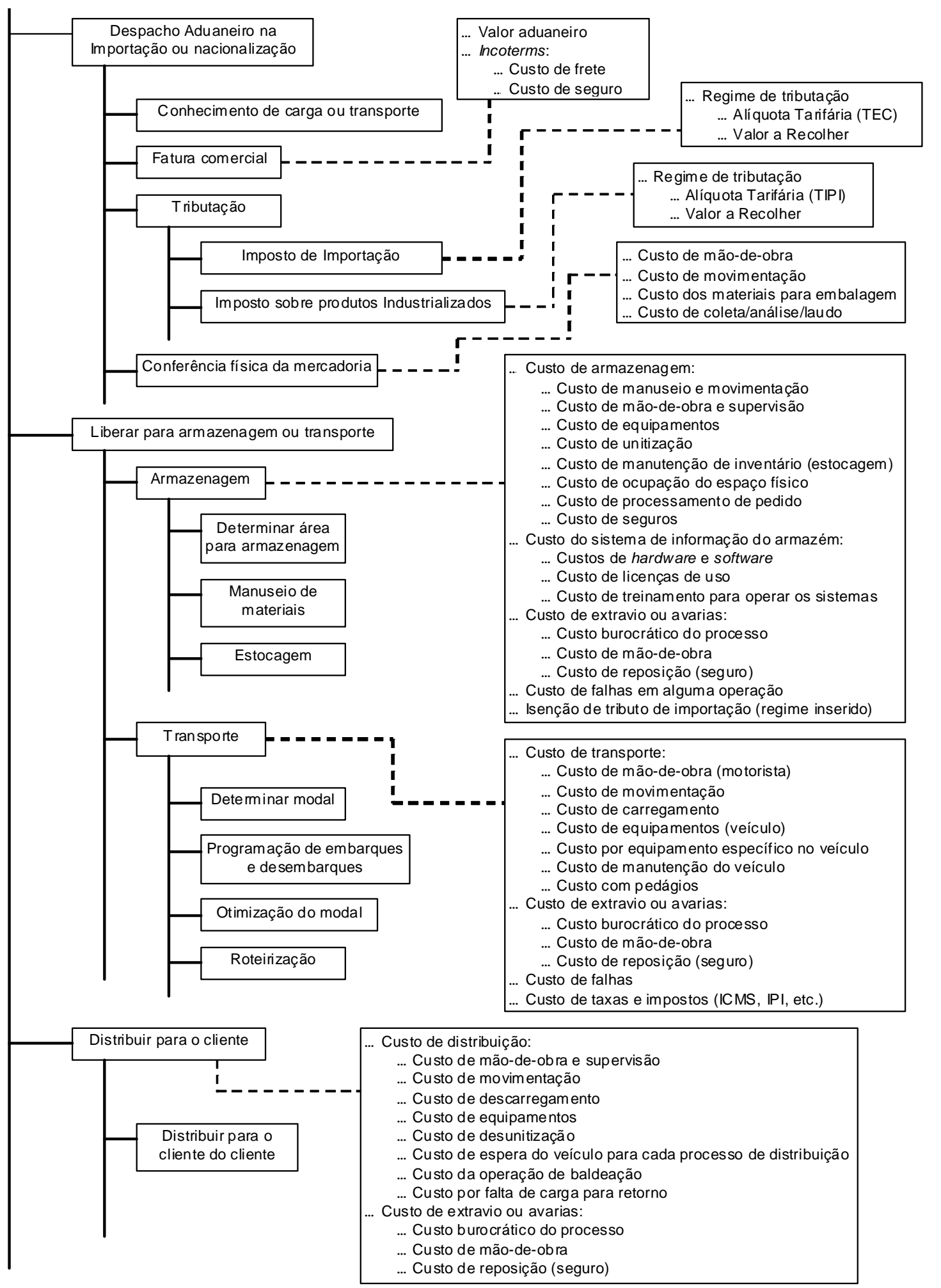

Figura 3 - Processo de importação sem Plataforma Logística e com TA de uso público (DUARTE, 2004, p. 163)

Neste processo são observadas as atividades e seus respectivos custos que acontecem no processo de exportação sem a utilização de um Terminal Alfandegado, e que não serão observados no processo com a Plataforma Logística.
O início do processo se dá quando o exportador providencia um despachante aduaneiro para realizar a operação de despacho de exportação via SISCOMEX - Sistema Integrado de Comércio Exterior, da Receita Federal. O exportador também deve providenciar a consolidação da mercadoria e o transporte até o porto ou aeroporto onde a 
mercadoria será embarcada e despachada, como pode ser observado na Figura 4.

\subsubsection{Processo de exportação sem plataforma logística e com TA de uso público}

O processo de exportação, observado na Figura 5, inicia quando o exportador firma contrato com o operador logístico do Terminal Alfandegado. Este se responsabiliza por ir ao estabelecimento do exportador preparar a mercadoria, embalando, consolidando e transportando até o Terminal Alfandegado, onde a mercadoria pode ficar ar-

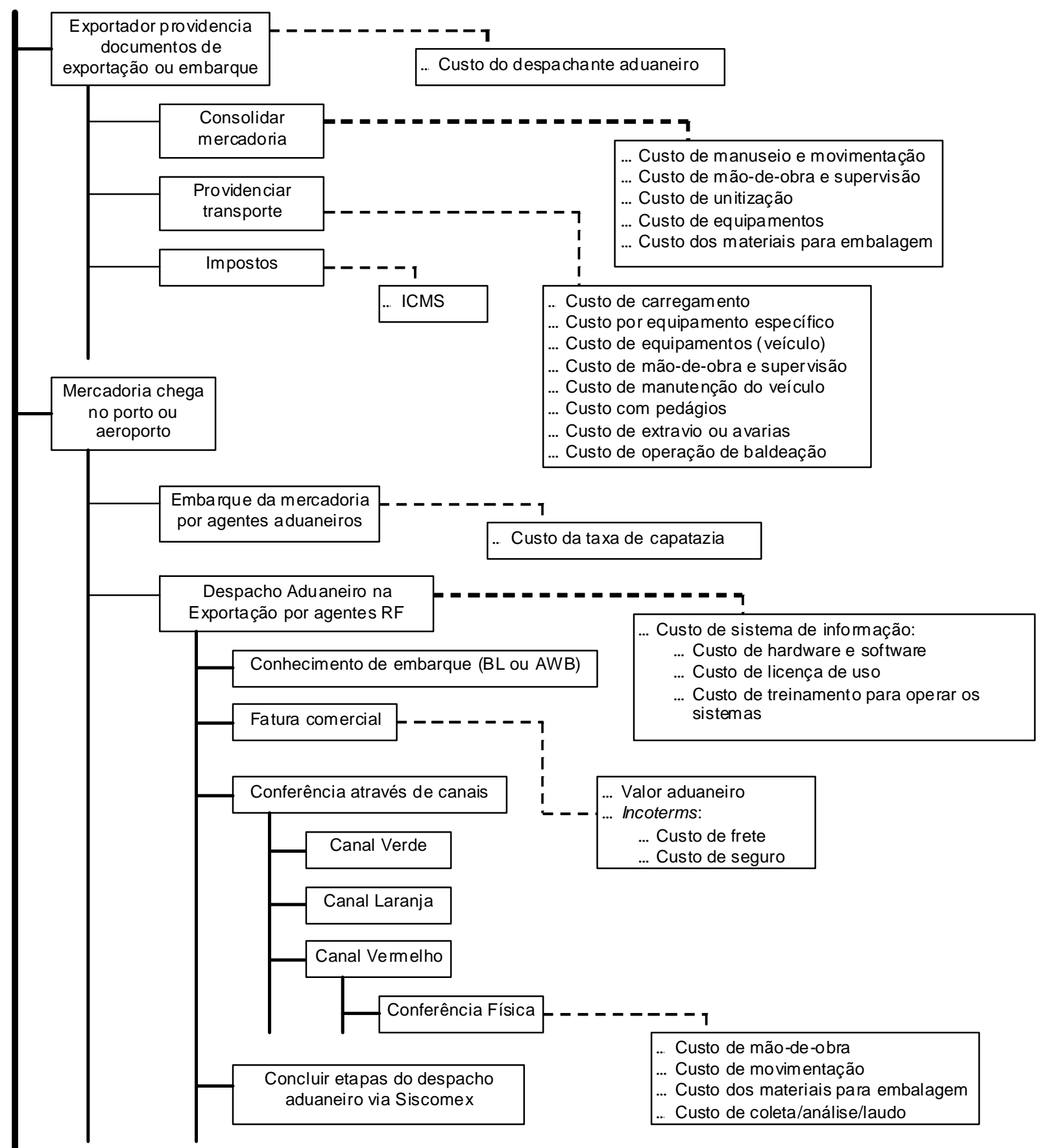

Figura 4 - Processo de exportação sem Plataforma Logística e sem TA de uso público (DUARTE, 2004, p. 166)

mazenada por alguns dias sem cobrança de armazenagem ou é enviada diretamente para o porto ou aeroporto para ser despachada.

Neste processo, cabe ao exportador a decisão por deixar a mercadoria armazenada no Terminal Alfandegado, visto que durante este processo a mercadoria fica isenta de taxas de armazenagem ou transportá-la diretamente para o porto ou aeroporto para o embarque. 


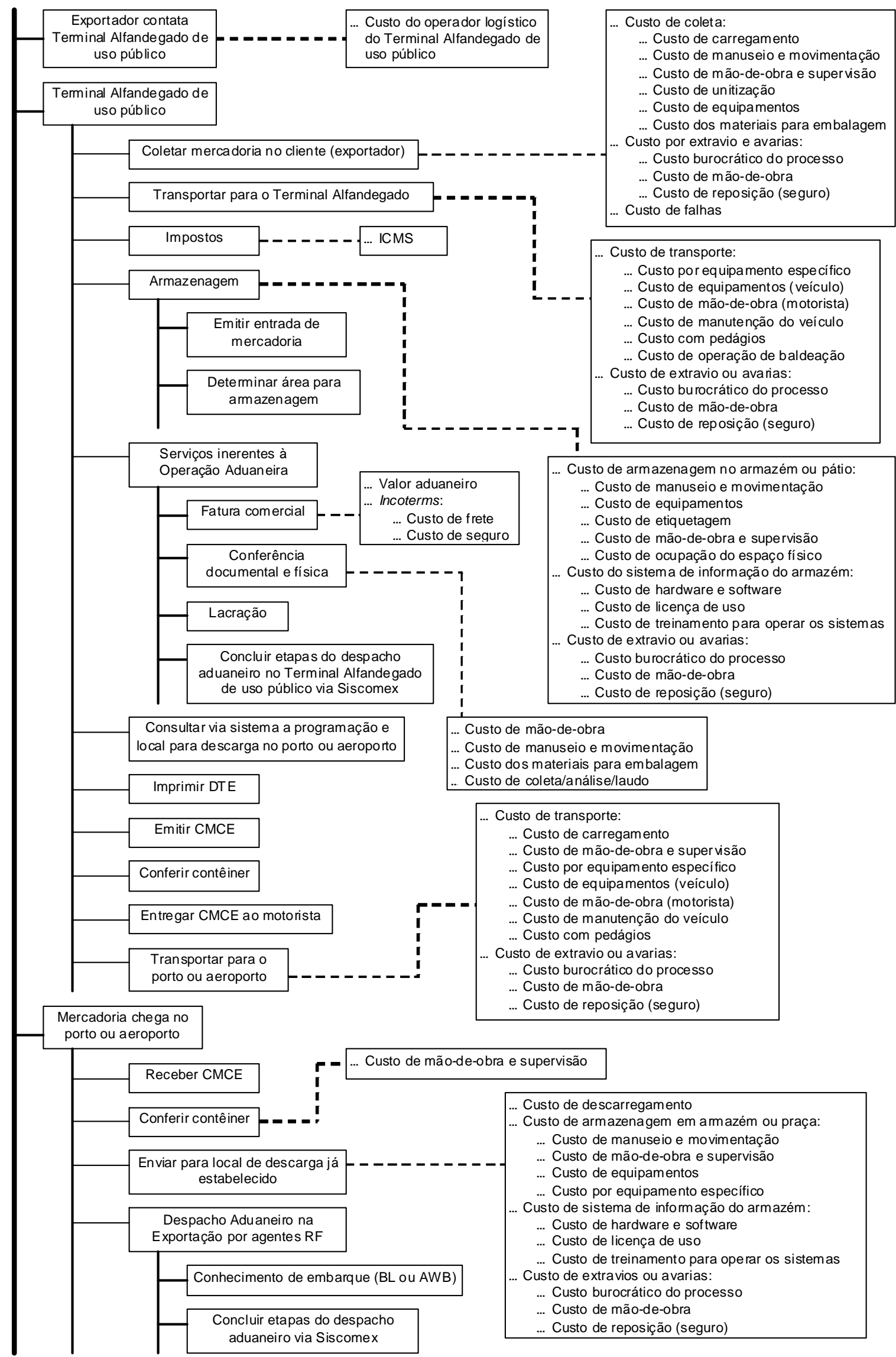

Figura 5 - Processo de exportação sem Plataforma Logística e com TA de uso público (DUARTE, 2004, p. 167) 


\subsection{Processo atual no mercado interno}

4.3.1 Processo no mercado interno sem plataforma logística

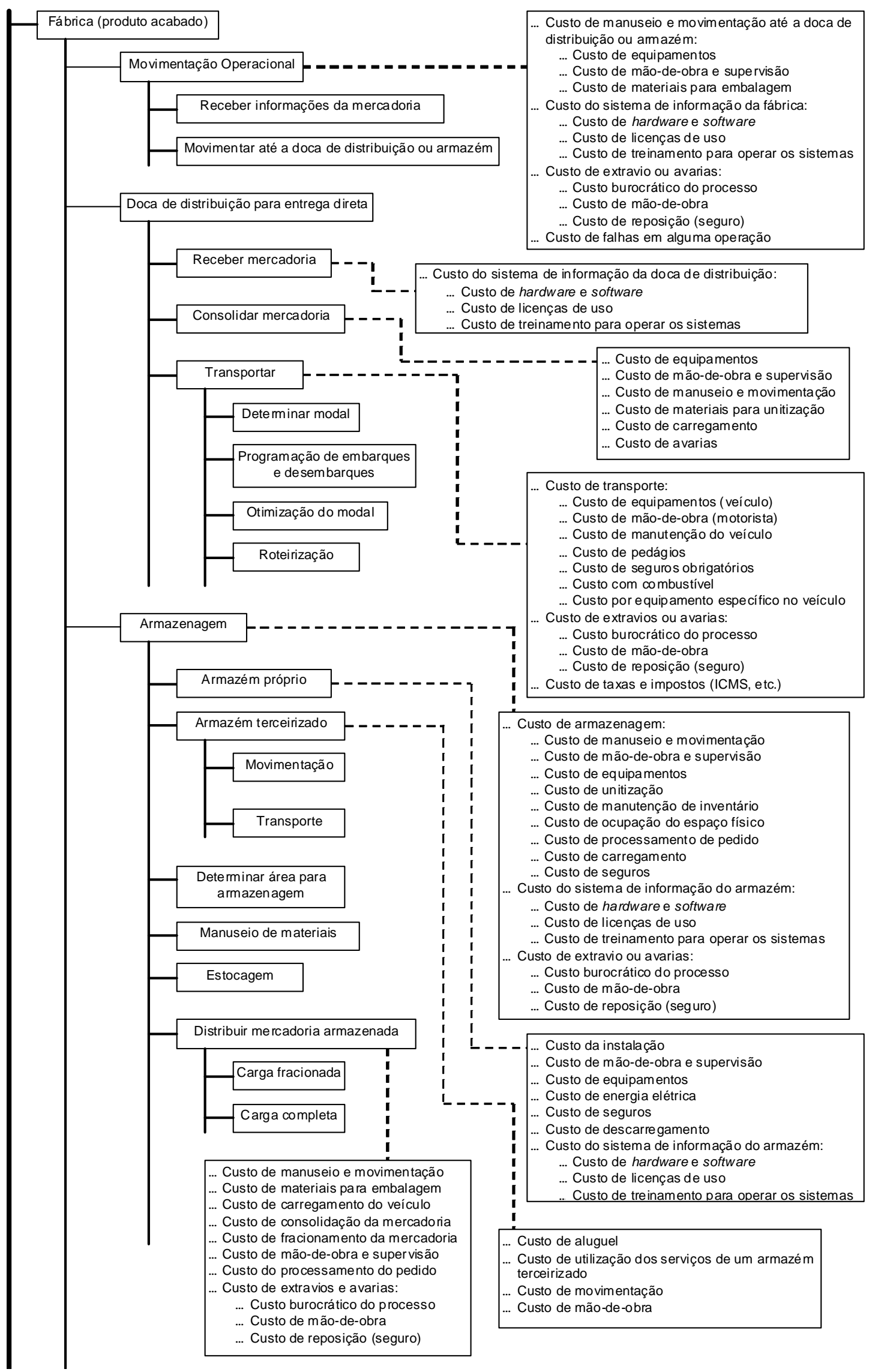




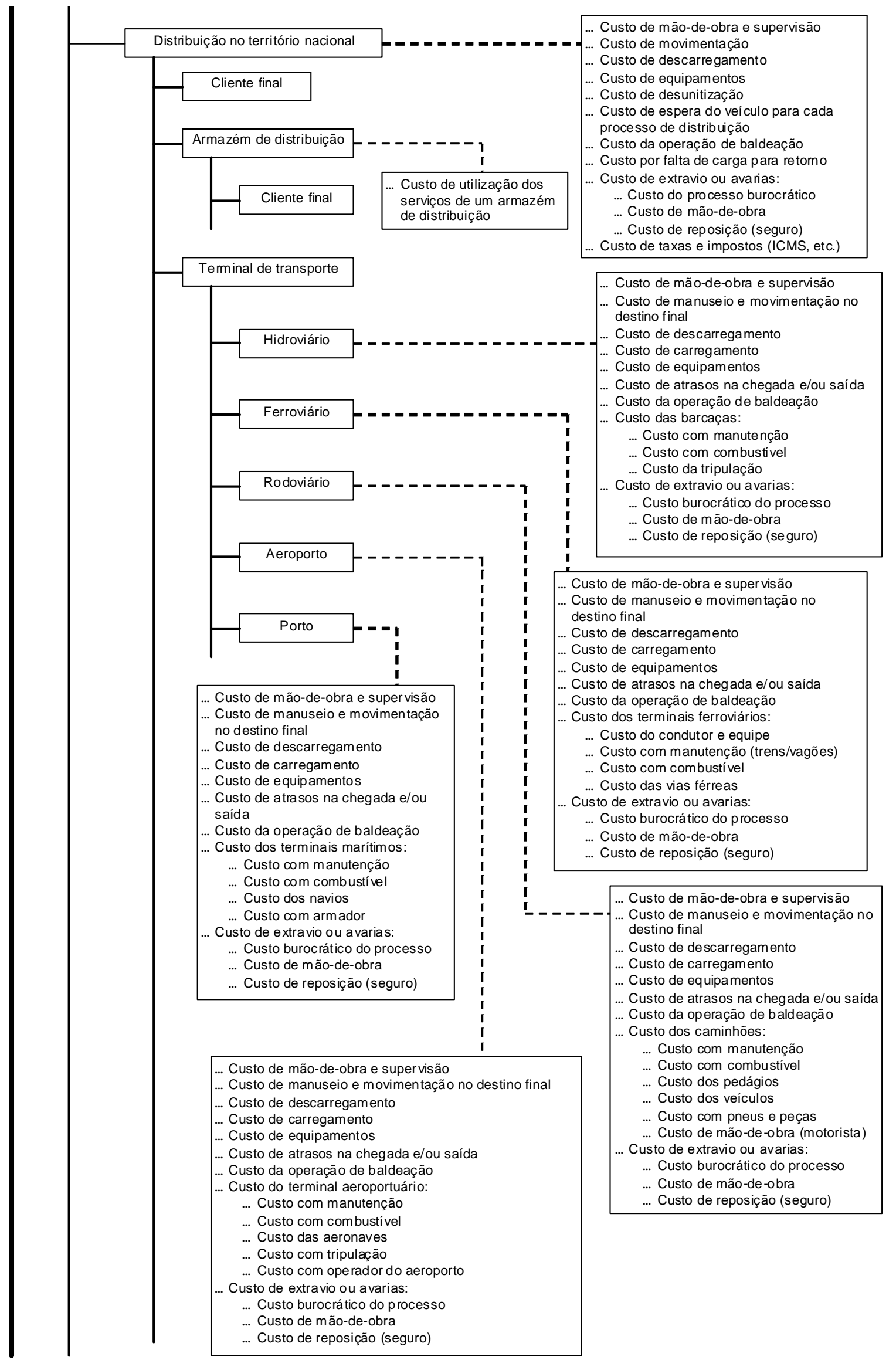

Figura 6 - Processo no mercado interno sem Plataforma Logística (DUARTE, 2004, p 169) 
Neste processo, todas as decisões com respeito à movimentação e circulação de mercadorias são de responsabilidade do proprietário da mercadoria (o fabricante, por exemplo). É ele quem decide pela terceirização ou utilização de serviços logísticos próprios, para as operações de embalagem, manuseio e movimentação, armazenagem, transporte, distribuição e todos os serviços que podem ser observados na Figura 6.

Neste processo, todas as atividades referentes à movimentação de mercadorias são realizadas pelo gerente da fábrica, que tem a responsabilidade de determinar o armazenamento ou entrega direta, tipos de embalagens, contratar o transporte e determinar o roteiro a ser seguido em caso de transporte próprio, etc., atividades estas que, através de um operador logístico pertencente à Plataforma Logística, são todas realizadas com rapidez e flexibilidade, pela grande disponibilidade de serviços oferecidos.

\section{Mapa estratégico para determinar os benefícios com a implantação de uma Plataforma Logística}

Após a observação do fluxo detalhado das atividades desenvolvidas em cada mercado de atuação da empresa em questão e, associando-se ainda os custos logísticos, pode-se aplicar o mapa estratégico de uma Plataforma Logística fazendo um levantamento dos critérios importantes no momento da tomada de decisão do usuário dos serviços logísticos, por um ou outro serviço.

Para isso, se faz necessário o trade-off entre os objetivos de desempenho e os custos relacionados a cada atividade. O resultado instantâneo pode apresentar nenhuma

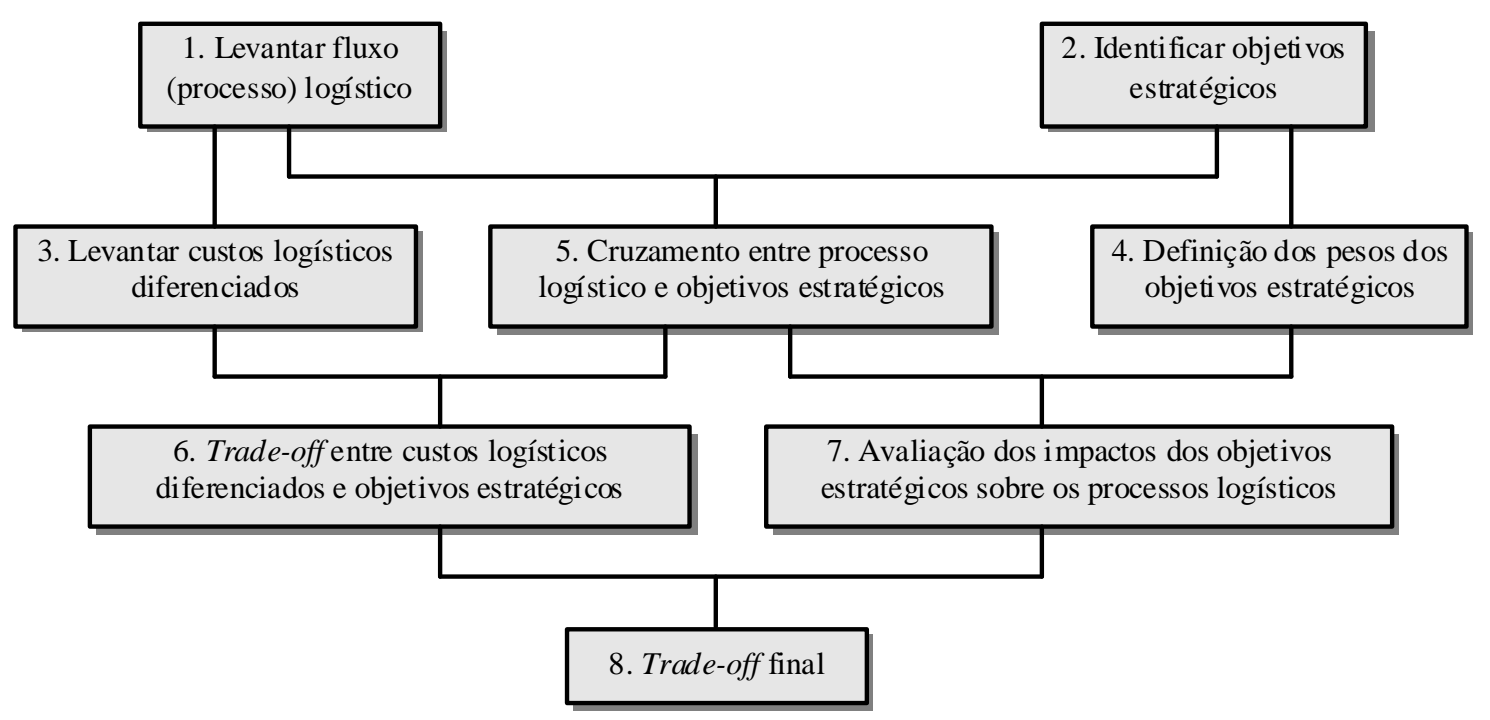

Figura 7 - Etapas que compõem o mapa estratégico (DUARTE, 2004, p. 180)

vantagem em termos de custo para o determinado serviço logístico, mas o resultado geral da cadeia, certamente apresentará maximização nos serviços e minimização no custo total envolvido.

Segundo Duarte (2004), o mapa estratégico para determinar os benefícios com a implantação de uma Plataforma Logística, observado na Figura 7, apóia-se em oito etapas nas quais, através dos trade-offs dos custos logísticos e seus respectivos objetivos de desempenho observado na população escolhida, serão apresentadas mudanças possíveis com a utilização da Plataforma Logística, ou seja, todas as relações custo e benefício que este sistema pode oferecer através de sua extensa rede. A relação entre a situação atual e a influenciada pela Plataforma Logística, determinará a presença ou não de vantagens estratégicas para a sua utilização e, em que relações essas vantagens se existirem são mais favoráveis.

\subsection{Descrição das etapas que compõem o mapa estratégico}

Para o início da construção do mapa estratégico, faz-se necessário uma descrição detalhada das etapas que o compõe. 


\section{Etapa 1 - Levantamento do fluxo (processo) logístico}

Nesta etapa será definido o mercado de atuação da empresa pesquisada: importação, exportação ou mercado interno, bem como os custos logísticos referentes às atividades de cada mercado. Serão também observados os processos referentes a cada mercado mencionado anteriormente, tendo a interferência dos serviços de uma Plataforma Logística. Terminado este levantamento, passa-se para a etapa seguinte, onde serão identificados os objetivos logísticos estratégicos da organização pesquisada.

Etapa 2 - Identificação dos objetivos logísticos estratégicos da organização

O objetivo desta etapa é identificar os objetivos de desempenho que atuam sobre os fluxos (processos) logísticos no mercado de atuação apresentado na etapa anterior. Para o melhor desempenho dos processos, relações devem ser ponderadas entre atividades envolvidas e objetivos logísticos estratégicos. Com a identificação dos objetivos logísticos estratégicos dos processos, passa-se para a etapa seguinte onde serão levantados os custos logísticos diferenciados.

Etapa 3 - Levantamento dos custos logísticos diferenciados
O objetivo dessa etapa é determinar os custos logísticos que surgem com a implementação da Plataforma Logística sobre os atuais processos de circulação de mercadorias. Ou seja, através da comparação dos fluxos anteriores, observados na Etapa 1, serão apontados as diferenças nos processos de mercado interno, exportação e importação de mercadorias. Levantados todos os custos logísticos que surgem com a implementação da Plataforma Logística sobre os processos existentes para movimentação de mercadorias, passa-se para a etapa seguinte onde serão determinados pesos dos objetivos estratégicos.

Etapa 4 - Definição dos pesos dos objetivos estratégicos

Nesta etapa serão definidos os pesos que irão estabelecer a relação entre os objetivos logísticos estratégicos e as atividades logísticas para preencher a matriz apresentada na Figura 8, o mesmo se dará na matriz apresentada na Figura 9. Definidos os pesos, inicia-se a etapa de avaliação dos impactos dos objetivos estratégicos sobre os processos logísticos proporcionados pela Plataforma Logística para as mesmas situações de mercado.

Etapa 5 - Cruzamento entre processos logísticos e objetivos estratégicos (menos os custos logísticos)

\begin{tabular}{|c|c|c|c|c|c|c|c|c|c|}
\hline \multirow{7}{*}{ 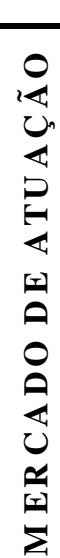 } & & & \multicolumn{6}{|c|}{ OBJETIVOS ESTRATÉGICOS } & \multirow[b]{2}{*}{$\begin{array}{c}\text { Nível de } \\
\text { influência } \\
\text { sobre os } \\
\text { processos }\end{array}$} \\
\hline & $\begin{array}{l}\text { Processos } \\
\text { Logísticos }\end{array}$ & $\begin{array}{c}\text { Grau de } \\
\text { importância }\end{array}$ & 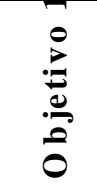 & 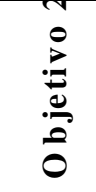 & 竞 & 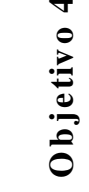 & $\vdots$ & $\frac{\stackrel{2}{e}}{.00}$ & \\
\hline & Processo 1 & & & & & & & & $\mathrm{VP}_{1}$ \\
\hline & Processo 2 & & & & & & & & $\mathrm{VP}_{2}$ \\
\hline & & & & & & & & & \multirow[b]{2}{*}{$\mathrm{VP}_{3}$} \\
\hline & Processo 3 & & & & & & & & \\
\hline & $\cdots$ & & & & & & & & $\cdots$ \\
\hline & Processon & & & & & & & & $V P_{n}$ \\
\hline & \multicolumn{2}{|c|}{ Peso relativo } & $\mathrm{VOb}_{1}$ & $\mathrm{VOb}_{2}$ & $\mathrm{VOb}_{3}$ & $\overline{\mathrm{VOb}}$ & $\ldots$ & $\mathrm{VOb}_{\mathrm{n}}$ & VTotal \\
\hline & \multicolumn{2}{|c|}{$\%$ peso relativo total } & & & & & & & $100 \%$ \\
\hline
\end{tabular}

Figura 8 - Matriz da relação entre processos logísticos e objetivos estratégicos (DUARTE, 2004, p. 191)

O objetivo desta etapa é identificar o nível de influência dos objetivos estratégicos sobre os processos logísticos nos mercado de atuação apresentados nas etapas 1 e 2. A matriz que representa esta relação entre objetivos e processos pode ser observada na Figura 8.
Para o melhor entendimento dos dados apresentados na matriz contida na Figura 8, serão definidos:

... Objetivos estratégicos: referentes às relações entre qualidade, rapidez, confiabilidade, flexibilidade e processos logísticos associados aos mercados de atuação; 
... Processos Logísticos: referem-se aos fluxos (processos) que podem ser observados nas figuras dos processos de importação, exportação e mercado interno;

... Mercado de atuação: mercado de atuação da empresa pesquisada (importação, exportação, interno);

... Grau de importância: serão definidos pelos gerentes das empresas pesquisadas, os graus ou pesos atribuídos aos fluxos (processos) logísticos, variando de 0 (zero) à 10 (dez), sendo zero atribuído a nenhuma importância e dez a importância máxima;

... $\quad$ Nível de influência sobre os processos (fluxos): será a soma das influências dos objetivos estratégicos sobre os respectivos processos logísticos;

... Peso relativo: será a soma dos pesos atribuídos aos objetivos estratégicos relacionados aos processos logísticos.

A determinação dos objetivos estratégicos que mais influenciam os processos logísticos nas atividades do mercado (importação, exportação, interno) será o que apresentar maior percentual do peso relativo total. Terminada esta etapa será necessário avaliar os impactos deste cruzamento.

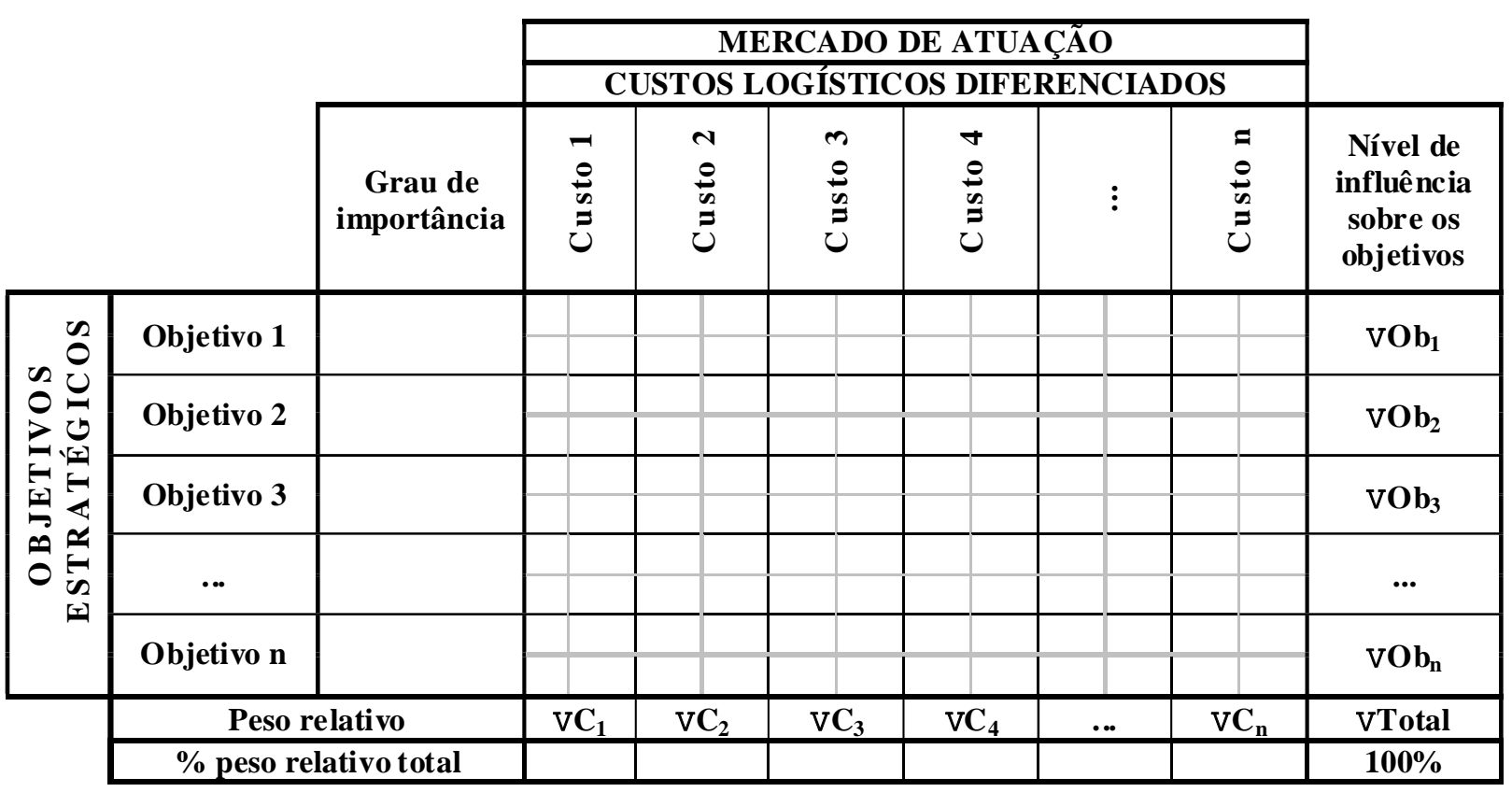

Figura 9 - Matriz da relação entre custos logísticos e objetivos estratégicos (DUARTE, 2004, p. 192)

Etapa 6 - Trade-off entre custos logísticos diferenciados e objetivos estratégicos

O objetivo desta etapa é identificar o nível de influência dos custos logísticos sobre os objetivos estratégicos no mercado de atuação. A matriz que representa esta relação (trade-off) entre custos e objetivos pode ser observada na Figura 9.

Para o melhor entendimento dos dados apresentados na matriz contida na Figura 9, serão definidos:

- Mercado de atuação: Mercado de atuação da empresa pesquisada (importação, exportação, interno); - Objetivos estratégicos: referentes às relações entre qualidade, rapidez, confiabilidade, flexibilidade e processos logísticos associados aos mercados de atuação; - Custos Logísticos Diferenciados: referem-se aos custos levantados na Etapa 3 deste mapa estratégico. Neste caso, os custos são referentes ao mercado de atuação; - Grau de importância: Serão as médias aritméticas dos pesos atribuídos aos objetivos estratégicos na etapa anterior de acordo com o peso da influência observado na Etapa 4;

- Nível de influência sobre os objetivos estratégicos: Será a soma das influências dos custos diferenciados sobre os objetivos estratégicos respectivos; - Peso relativo: será a soma dos pesos atribuídos aos custos logísticos diferenciados relacionados aos objetivos estratégicos.

A determinação dos custos logísticos diferenciados que mais influenciam os objetivos estratégicos nas atividades do mercado de atuação, será o que apresentar maior percentual do peso relativo total. Terminada esta etapa será necessário avaliar os impactos deste cruzamento, bem como definir os pesos para a análise final de onde são maior ou menor os benefícios com a utilização dos serviços propostos pela Plataforma Logística em um segmento de mercado. 
Etapa 7 - Avaliação dos impactos dos objetivos estratégicos sobre os processos logísticos

Nesta etapa é realizada a análise dos cruzamentos realizados anteriormente nas Etapas 4 e 6, a fim de determinar onde é maior ou menor a relação entre um objetivo estratégico (qualidade, flexibilidade, rapidez e confiabilidade) e o processo logístico possibilitando uma melhor análise e escolha por um ou outro serviço.

Etapa 8 - Trade-off final

Terminadas todas as etapas, é possível determinar onde e quanto à implementação de uma Plataforma Logística pode melhorar ou não a circulação de mercadorias e conseqüentemente, reduzir custos inseridos nos processos logísticos através do proporcionamento de objetivos estratégicos como, qualidade, flexibilidade, rapidez e confiabilidade.

\subsection{Aplicação do mapa estratégico no setor conserveiro}

A aplicação do mapa estratégico iniciou com o levantamento dos mercados de atuação (interno, exportação e importação) do setor de produção de conservas (DUARTE, 2004), localizado no extremo sul do Estado, bem como os custos logísticos referentes às atividades de cada mercado. Através deste levantamento, foi possível determinar as atividades logísticas mais presentes nos mercados de atuação das indústrias de conservas e que concentram os principais custos logísticos para o setor. As principais atividades logísticas observadas foram: transporte, movimentação operacional, consolidação de mercadorias, despachante aduaneiro, etc.

Terminada esta etapa, prosseguiu-se para a identificação dos objetivos logísticos estratégicos do setor por atividades logísticas para os mercados de atuação, observando-se, por exemplo: rapidez na expedição do pedido, reduzir movimentação interna, rapidez para liberar mercadoria (greves), flexibilidade para alterar programações, confiabilidade no prazo de entrega, etc.

Após a identificação dos objetivos estratégicos foram levantados os custos logísticos diferenciados, ou seja, aqueles afetados pela implantação de uma Plataforma Logística diante do atual sistema de movimentação e armazenagem de produtos. Os resultados obtidos foram: custo de pedágios, custo de taxas e impostos (ICMS, etc.), custo de equipamentos, custo de manuseio e movimentação, custo de materiais para embalagens, etc.

Com as observações feitas, aplicou-se o mapa estratégico sobre as necessidades do setor conserveiro gaúcho, possibilitando diagnosticar onde e de que forma a implanta- ção de uma Plataforma Logística se faz necessária.

\subsubsection{Resultado da aplicação do mapa estratégico no setor conserveiro}

As análises foram observadas sobre três óticas de atuação do setor conserveiro: mercado interno, onde todas as indústrias de conservas pesquisadas atuam e, exportação e importação onde 60\% das mesmas atingem um mercado satisfatório para a manutenção de suas vantagens competitivas.

No mercado interno, a partir do momento que o setor conserveiro aferiu graus de importância às atividades logísticas, foi possível perceber a preocupação com relação ao "transporte" (28\%). Este, na maioria das indústrias pesquisadas, é realizado por empresas terceirizadas, que em muitas situações exigem o transporte de cargas completas, atrasando a distribuição das indústrias ou encarecendo o frete. Algumas reclamações sobre esta atividade também se referem aos atrasos nas entregas por parte dos transportadores, não cumprindo os contratos indústriacliente, acarretando suspensão de contratos e devolução de produtos. Estes fatores podem ser observados nos objetivos estratégicos que mais influenciam esta atividade: "confiabilidade no prazo de entrega" (20\%) e "rapidez na entrega para atender o pedido" (17\%).

A segunda maior preocupação do setor refere-se à atividade "consolidação de mercadorias", que é fortemente afetada pelos objetivos estratégicos: "qualidade no serviço de consolidação" e "qualidade nos materiais de embalagens". Estes fatores refletem a qualidade do produto final e a satisfação do cliente, pois embalagens amassadas são devolvidas às indústrias, acarretando custos de transporte de retorno, reposição de produtos, cancelamento de pedidos, etc. Além do que, a qualidade no serviço de consolidação, interfere de maneira direta em todas as atividades da indústria como, em uma ágil movimentação operacional, no transporte e distribuição além de facilitar a armazenagem e acondicionamento dos produtos.

Quanto ao mercado de atuação, exportação, a atividade "transporte" (59\%) tem uma importância muito maior do que a apresentada no mercado anterior, isto se deve à rapidez com que o setor conserveiro deseja atingir e satisfazer mercados internacionais. Muitas das indústrias terminam suas produções e já preparam a distribuição direta, sem armazenagem, prova disso, que a atividade logística "armazenagem" não obteve importância atribuída como as demais atividades. Além do que, os objetivos estratégicos mais pretendidos pelo setor conserveiro estão fortemente relacionados a esta rapidez em atingir mercados: "qualidade na entrega e no manuseio de produtos" (25\%) e "confiabilidade no prazo de entrega" (25\%) e, também, a grande preocupação com relação aos serviços aduanei- 
ros, onde as constantes greves de agentes da Receita Federal prejudicam a liberação dos produtos à exportação, causando quebras de contratos e aumento dos custos de armazenagem aduaneira e serviços correlatos. Isto pode ser observado nos objetivos estratégicos almejados pelo setor conserveiro como: "rapidez para liberar a mercadoria (greve)" e "flexibilidade para alterar programações", pois os agentes da Receita possuem horários muito rígidos para a fiscalização, vistoria e liberação da mercadoria à exportação, causando atrasos e custos adicionais em toda a rede.

A importação é um mercado de acesso para insumos que venham a completar os insumos nacionais para a produção de conservas pelo setor. Das indústrias entrevistadas para esta pesquisa, apenas duas utilizam apenas produtos nacionais. Dentro deste mercado de atuação, embora tenha recebido o segundo maior grau de importância pelo setor conserveiro, a atividade logística "transporte" (47\%), assim como nos demais mercados de atuação, também foi a mais influenciada das atividades pelos objetivos estratégicos, tendo uma grande correlação com a atividade apontada pelos entrevistados como a mais importante "despachante aduaneiro" (31\%), onde a "rapidez para liberar a mercadoria" (25\%) e a "confiabilidade a respeito das informações sobre a mesma" (24\%) são as maiores preocupações do setor.

No processo de importação, o grande vilão na maioria das vezes, como na exportação, é a greve dos agentes aduaneiros, que mantém nas fronteiras os produtos, em sua maioria para este setor, perecíveis, causando prejuízos com relação ao transporte (caminhões detidos nas aduanas), a movimentação operacional (fábrica) com atrasos na produção e custos adicionais de mão-de-obra parada, além, de atrasos ou não cumprimentos de contratos com os clientes.

Com as observações feitas, aplicou-se o mapa estratégico sobre as necessidades do setor conserveiro gaúcho, possibilitando diagnosticar onde e de que forma a implantação de uma Plataforma Logística se faz necessária, e pôdese notar que, dentre as atividades logísticas mais relevantes, o transporte detém a maior problemática e afere os maiores custos logísticos. Isto se deve em parte ao monopólio do transporte rodoviário, das péssimas condições das rodovias (estaduais e federais), da quantidade exorbitante de impostos, taxas e tributos pagos para a movimentação de produtos.

É claro que a utilização dos serviços de uma Plataforma viria a interferir na movimentação propriamente dita, e não na questão tributária, mas, de certa forma, já influenciaria de maneira positiva na qualidade do serviço prestado. Outros benefícios com relação à atividade "transporte", utilizando os serviços disponibilizados pela Plataforma Logística, dizem respeito à utilização de equipamentos específicos para movimentação dos produtos, transporte adequado às necessidades da indústria e do cliente, armazenagem, gerenciamento de estoque, fracionamento da carga, consolidação/desconsolidação e distribuição, ou seja, a Plataforma passa a ser concebida como uma extensão da fábrica e de suas atividades.

\section{Conclusões}

Realizadas todas as análises com a implantação do mapa estratégico de uma Plataforma Logística sobre o setor conserveiro, foi possível observar onde os serviços logísticos proporcionados por uma Plataforma influenciariam as atividades e os custos encontrados hoje no setor ao movimentar seu produto (conservas) no mercado interno, exportação e importação.

Junto aos usuários/clientes, os reflexos com a implantação de um sistema integrado como a Plataforma Logística serão significativamente positivos. Estes reflexos poderão ser percebidos com a agilização na movimentação operacional, desburocratização aduaneira, informação detalhada e atualizada do processo e transporte, desde o momento do contato do cliente com o operador logístico da Plataforma até a distribuição final.

Como este mapa estratégico de uma Plataforma Logística trata-se de uma inferência de possíveis possibilidades, os resultados são especulações a respeito de melhoras em certas atividades problemáticas e que detém a maioria dos custos totais dos serviços oferecidos. É evidente que, para uma correta análise, teríamos que dispor do total funcionamento de uma Plataforma Logística, operando em condições reais, o que não ocorre hoje no Brasil. Além do que, a implantação de uma Plataforma Logística só teria uma plausível justificativa para a movimentação, armazenagem e distribuição de produtos e clientes diversos, que justificariam o oferecimento de serviços diferenciados como, por exemplo, o transporte de carga não completa para um cliente; rapidez na entrega e alterações de programações de embarque.

Portanto, se faz necessário uma análise de outros possíveis clientes para a Plataforma Logística que viriam a justificar este tipo de investimento hoje no Estado e até mesmo no país, como, por exemplo, outros setores produtivos, que produzem mercadorias diversas e atuam em mercados e períodos variados.

\section{Referências}

ASSOCIAÇÃO GAÚCHADACADEIAAGRO-INDUSTRIAL DE FRUTAS E HORTALIÇAS. Pesquisa de mercado para identificar as variáveis intervenientes na dinâmica do mercado de "Pêssego em Calda". Pelotas, 06/ $\mathrm{abr} / 2004$. 
BACOVIS, M. M. Estudo comparativo das Plataformas Logísticas européias $\mathrm{x}$ brasileiras, como forma de identificar um modelo que atenda as empresas do PIM. In: CONGRESSODEPESQUISAEINOVAÇÃODAREDENORTE NORDESTE DE EDUCAÇÃO TECNOLÓGICA, Paraíba. Anais eletrônicos... João Pessoa, 2007, 1CD.

BELLO, T. S.; TERUCHKIN, S. U.. Relações Internacionais - As exportações do RS em 2005. Revista Indicadores FEE - v. 33, n. 4. Porto Alegre, RS: FEE, 2006. Disponível em: <http://www.fee.rs.gov.br/sitefee/download/indicadores/33_04/7_parte.pdf>.Acesso em: 20 abr. 2006.

BOUDOUIN, D. Logística-Território-Desenvolvimento: O caso europeu. I Seminário Internacional: Logística, Transportes e Desenvolvimento. Ceará: UFC/CT/DET, 1996, p. 103-111.

COLIN, J. Les evolutions de la logistique en Europe: vers la polarisation des espaces. I Seminário Internacional: Logística, Transportes e Desenvolvimento. Ceará: UFC/ CT/DET, 1996, p. 52-92.

DORNIER, P.; ERNST, R.; FENDER, M.; KOUVELIS, P. Logística e operações globais: textos e casos. São Paulo: Atlas, 2000, $721 \mathrm{p}$.

DUARTE, P. C.; RODRIGUES, C. T. Plataforma Logística: Um modelo para os portos brasileiros. In: SIMPÓSIO DE PESQUISA OPERACIONAL E LOGÍSTICA DA MARINHA, Rio de Janeiro. Anais eletrônicos... Rio de Janeiro, 1998, 1 CD.

DUARTE, P. C. Modelo para o desenvolvimento de Plataforma Logística em um Terminal: Um estudo de caso na Estação Aduaneira do Interior - Itajaí/SC. Dissertação de Mestrado. Programa de Pós-Graduação em Engenharia de Produção. Florianópolis. UFSC, 1999a , 100 p.

DUARTE, P. C. Modelo para o desenvolvimento de Plataforma Logística em um terminal. In: SIMPÓSIO DE PESQUISA OPERACIONAL E LOGÍSTICA DA MARINHA, Rio de Janeiro. Anais eletrônicos... Rio de Janeiro, 1999b, $1 \mathrm{CD}$.

DUARTE, P. C. Plataforma Logística como um processo de clusterização: Uma possibilidade para os setores produtivos do Rio Grande do Sul. In: ENCONTRO NACIONAL DE ENGENHARIADE PRODUÇÃO, Minas Gerais. Anais eletrônicos... Ouro Preto, 2003, 1CD.

DUARTE, P. C. Desenvolvimento de um mapa estratégico para apoiar a implantação de uma Plataforma Logística. Tese de Doutorado. Programa de Pós-Graduação em Engenharia de Produção. Porto Alegre. UFRGS,
2004, 284p.

DUARTE, P. C. Avaliação estratégica na utilização dos serviços proporcionados pela Plataforma Logística para potenciais clientes/usuários. Global Manager, Revista do Curso de Administração da Faculdade da Serra Gaúcha v. 5, n. 9 (2005). Caxias do Sul, RS: FSG, 2005, p. 137 - 152.

LACERDA, L. Armazenagem estratégica: analisando novos conceitos. In: FLEURY, P.; WANKE, P. e FIGUEIREDO, K. Logística empresarial: a perspectiva brasileira. São Paulo:Atlas, 2000, p. 154-160.

MARINO, S. A voz e a vez dos embarcadores. São Paulo: Publicare Editora Ltda. Revista Tecnologística, ano IX, n. 95, Outubro de 2003, p. 72-80.

RIO GRANDE DO SUL (Estado). Secretaria do Desenvolvimento e dos Assuntos Internacionais. Identificação e análise de informações sobre os sistemas locais de produção do RS: Relatório para o sistema local de produção de conservas. Porto Alegre, 2000. NITEC/PPGA/UFRGSFAURGS.

SCHETTERT, M. C. Contas Regionais - Desempenho da economia gaúcha em 2005. Revista Indicadores FEE - v. 33, n. 4. Porto Alegre, RS: FEE, 2006. Disponível em: <http:/ /www.fee.rs.gov.br/sitefee/download/indicadores/33_04/ 2_parte.pdf >. Acesso em: 20 abr. 2006. 